\title{
Synthesis and Characterization of Methylcellulose from Cellulose Extracted from Mango Seeds for Use as a Mortar Additive
}

\author{
Júlia G. Vieira, Guimes Rodrigues Filho, Carla da S. Meireles, Fernanda A. C. Faria, Dayane D. Gomide, Daniel Pasquini \\ Instituto de Química, UFU \\ Sebastião F. da Cruz \\ Instituto de Química, UFU \\ Departamento de Química, UNIUBE
}

Rosana M. N. de Assunção

Faculdade de Ciências Integradas do Pontal, UFU

Leila A. de C. Motta

Faculdade de Engenharia Civil, UFU

\begin{abstract}
Methylcellulose was produced from the fibers of Mangifera indica L. Ubá mango seeds. MCD and MCI methylcellulose samples were made by heterogeneous methylation, using dimethyl sulfate and iodomethane as alkylating agents, respectively. The materials produced were characterized for their thermal properties (DSC and TGA), crystallinity (XRD) and Degree of Substitution (DS) in the chemical route. The cellulose derivatives were employed as mortar additive in order to improve mortar workability and adhesion to the substrate. These properties were evaluated by means of the consistency index (CI) and bond tensile strength (TS) tests. The methylcellulose (MCD and MCI) samples had CI increased by 27.75 and $71.54 \%$ and TS increased by 23.33 and $29.78 \%$, respectively, in comparison to the reference sample. Therefore, the polymers can be used to produce adhesive mortars.
\end{abstract}

Keywords: Mango seed, cellulose, methylcellulose, mortar, additives.

\section{Introduction}

Paper pulp is the main source of cellulose but in the literature there are a number of studies concerning the development of several agribusiness wastes for this purpose. The growing use of cellulose extracted from alternative sources such as sugarcane bagasse, rice straw, coconut husks and others is emphasized ${ }^{[1-4]}$.

One of the main agribusinesses in Brazil is fruit farming which has increased in recent years. In 2004, Brazil was the ninth world producer of mangos with $3.4 \%$ of the total volume worldwide and an annual production of 823 thousand tons ${ }^{[5]}$. The following varieties are cultivated: Tommy Atkins, Haden, Keith, Palmer and Ubá $^{[6]}$.

In the Triângulo Mineiro (Minas Gerais) region, in Araguari alone, 1,300 tons/year of mango seeds are produced ${ }^{[7]}$. They are a major source of waste and their potential for cellulose derivatives should be investigated.

In our research group, The Group of Polymer Recycling of the Universidade Federal de Uberlândia (GRP-UFU), mango seeds have also been a source of cellulose for the production of cellulose derivatives, such as cellulose acetate to manufacture asymmetrical membranes ${ }^{[8]}$ and methylcellulose ${ }^{[9]}$.

Methylcellulose is extensively applied in the pharmaceutical, food, petrochemical, civil construction and other industries ${ }^{[1,10,11]}$. Its use is directly related to the degree of substitution (DS) that influences its physical properties such as water solubility.

Methylcellulose is a methyl ether that can be produced by a reaction between cellulose in an alkaline medium, with a methylating agent, such as methyl iodide, methyl chloride or dimethyl sulfate (DMS) $)^{[1,12]}$. Different DS can be obtained altering the synthesis conditions, such as the reaction time or the methylating agent ${ }^{[1]}$.
In civil construction, methylcellulose and other ethers such as hydroxyethyl cellulose (HEC), hydroxypropyl methylcellulose (HPMC), hydroxyethylmethyl cellulose (HEMC) e carboxymethyl cellulose (CMC) are generally used in industrial mortar formulas to improve the workability of the fresh mortar and adhesion to the substrate ${ }^{[13,14]}$. These macromolecules also significantly increase the water-retention capacity and paste viscosity. These admixtures can also reduce the risk of separation of heterogeneous constituents of concrete during transport and storage, stabilizing the concrete while fresh. Because they result in highly viscous systems with a good water retention capacity and adhesion, these polymers are often used to produce mortars for tile-laying ${ }^{[15,16]}$.

Our group began to produce methylcellulose from sugarcane bagasse with a reaction time of 3 hours and using DMS as the methylating agent. In this way we obtained a DS of $1.20^{[1]}$. Although the DS value was high, the material was not watersoluble and thus it was difficult to apply as an additive for mortars in civil construction. Later the material was produced with a 3 hours reaction time and successive changes of reagents, and a DS of 1.40 was obtained ${ }^{[17]}$. Although it was within the DS range of the water-soluble materials (1.40 to 2.00), according to the literature $^{[18,19]}$, it was not sufficiently soluble to use as a mortar additive. In a further study of synthesis, the reaction time was changed to 5 hours, with successive reagent changes, and the resulting material was obtained with a DS of 1.89 , which made it possible to prepare an aqueous suspension of the polymer that was applied as a mortar additive in civil construction ${ }^{[20]}$. The latter synthesis pathway was also used to produce methylcellulose based on newspaper cellulose which was used as a mortar additive in civil construction, with satisfactory results ${ }^{[16]}$.

Autor para correspondência: Guimes Rodrigues Filho, Instituto de Química, Universidade Federal de Uberlândia - UFU, Av. João Naves de Ávila, 2121, CP 593, CEP 38400-902, Uberlândia, MG, Brasil, e-mail: guimes.rodriguesfilho@gmail.com; guimes@ufu.br 
In the present study, mango seeds (the outer part called integument) of the Mangifera indica L., Ubá variety, were used as another alternative source of cellulose for methylcellulose production used as a mortar additive. Studies were also performed to improve the solubility of the material using iodomethane as a methylating agent. This synthesis pathway was also used because both aqueous solutions and cellulose ether suspensions have been widely utilized as additives to produce mortars and concretes in the building industry ${ }^{[10,21-23]}$. The materials made with DMS and iodomethane were characterized by Fourier Transform Infrared Spectroscopy (FTIR), Differential Scanning Calorimetry (DSC), Thermogravimetric Analysis (TGA), X ray Diffraction (XRD) and determining the Degree of Substitution (DS) by chemical route. The material produced was used for tests as a mortar additive for laying tiles, coatings and finishing.

\section{Experimental Procedure}

\section{Ubá mango seed delignification}

Crude mango seeds (CS) were delignified as described in Meireles $^{[7]}$. A $10 \mathrm{~g}$ sample of dry and ground mango seed was refluxed for 3 hours with a $20 \%$ (v/v) solution of nitric acid/ethanol. The material was filtered hourly and a new amount of solution was added. After reflux the mixture was washed with distilled water until the solution water was clear. Next, $40 \mathrm{~mL}$ of a solution of $\mathrm{NaOH} 1.0$ mol. $\mathrm{L}^{-1}$ were added. After 24 hours the material was neutralized with an acetic acid 10\% (v/v) solution and washed with distilled water until a neutral $\mathrm{pH}$ was reached. The delignified mango seed (DSE) was dried in the oven at $105{ }^{\circ} \mathrm{C}$ for 3 hours and then desintegrated ground using a blender.

\section{Characterization of crude mango seeds (CS) and delignified mango seeds (DSE)}

The Klason lignin content was determined using the procedure described in standard TAPPI 222 om-02. In this methodology, the polysaccharides are removed by hydrolysis with sulfuric acid solution (72\%), leaving as a residue of this process, the lignin ${ }^{[24]}$

The cellulose content was determined using the procedure described in standard TAPPI $235 \mathrm{~cm}-00$. This methodology is based in the isolation of the holocellulose, constituted by cellulose and hemicelluloses, by the acid chlorite method and successive extraction of the hemicelluloses with potassium hydroxide solution 5 and $24 \%$. At the end of this process, the cellulose is quantified ${ }^{[25]}$.

\section{Methylcellulose synthesis}

\section{Methylcellulose (MCD) synthesis using dimethyl sulfate (DMS)}

The methodology described by Vieira et. al. ${ }^{[20]}$ was used to methylate the fibers of the delignified mango seed (DSE). About $1 \mathrm{~g}$ of DSE was initially mercerized using $20 \mathrm{~mL}$ of a sodium hydroxide $(\mathrm{NaOH}) 50 \%(\mathrm{w} / \mathrm{v})$ solution for 1 hours at ambient temperature. After this time, the mixture was filtered to remove the excess of sodium hydroxide. Nine $\mathrm{mL}$ of acetone PA and $3 \mathrm{~mL}$ of dimethyl sulfate (DMS) were added to the mixture. It was left to react for 5 hours at $50{ }^{\circ} \mathrm{C}$ by shaking in a closed system, and the reaction mixture ( $9 \mathrm{~mL}$ of acetone, $3 \mathrm{~mL}$ DMS) was changed hourly. Finally the mixture was neutralized with an acetic acid at $10 \%(\mathrm{v} / \mathrm{v})$ solution and filtered in a syntherized plate funnel, and washed with three successive portions of acetone. The final product obtained (methylcellulose - MCD) was dried in an oven at $50{ }^{\circ} \mathrm{C}$ for 6 hours.

\section{Methylcellulose (MCl) synthesis using iodomethane}

The procedure was adapted from Ye \& Farriol ${ }^{[12]}$, as now described: $120 \mathrm{~g}$ of an aqueous solution of $\mathrm{NaOH} 50 \%$ were added to $5 \mathrm{~g}$ of DSE, and left for 1 hours (mercerization). After mercerization the mixture was filtered, leaving $15 \mathrm{~mL}$ of $\mathrm{NaOH}$ as residue. Then $300 \mathrm{~mL}$ of isopropanol were added and the material was shaken for 1 hours at room temperature $\left(25^{\circ} \mathrm{C}\right)$. Fifty $\mathrm{mL}$ of iodomethane were added and the mixture was shaken for another 1 hours. Then the mixture was left to reflux at a temperature of $60{ }^{\circ} \mathrm{C}$ for 22 hours. The mercerization and methylation procedures were repeated once more for the same sample in order to obtain a methylcellulose with a higher degree of substitution. The mixture was neutralized with glacial acetic acid and filtered. The resulting methylcellulose (MCI) was washed with ethanol and acetone three times, respectively, and dried in the oven at $60{ }^{\circ} \mathrm{C}$.

\section{Determination of the degree of substitution (DS)}

The procedure to determine the contents of the methoxyl groups in the sample was described by Vieira et al. ${ }^{[1]}$. The method is based on the reaction between the sample and the iodidric acid to form methyl iodide, according the following reaction:

$$
\mathrm{ROCH}_{3}+\mathrm{HI} \rightarrow \mathrm{ROH}+\mathrm{CH}_{3} \mathrm{I}
$$

Methylcellulose

The percentage of methoxyl groups and later the degree of substitution are determined through indirect volumetry of the iodine released by a series of chemical reactions, which are represented bellow:

$$
\begin{aligned}
& \mathrm{CH}_{3} \mathrm{I}+\mathrm{Br}_{2} \rightarrow \mathrm{CH}_{3} \mathrm{Br}+\mathrm{IBr} \\
& \mathrm{IBr}+3 \mathrm{H}_{2} \mathrm{O}+2 \mathrm{Br}_{2} \rightarrow \mathrm{HIO}_{3}+5 \mathrm{HBr} \\
& \mathrm{HIO}_{3}+5 \mathrm{KI}+5 \mathrm{H}^{+} \rightarrow 3 \mathrm{I}_{2}+3 \mathrm{H}_{2} \mathrm{O}+5 \mathrm{~K}^{+} \\
& 3 \mathrm{I}_{2}+6 \mathrm{Na}_{2} \mathrm{~S}_{2} \mathrm{O}_{3} \rightarrow 6 \mathrm{NaI}+3 \mathrm{Na}_{2} \mathrm{~S}_{4} \mathrm{O}_{6}
\end{aligned}
$$

\section{Fourier transform infrared spectroscopy (FTIR) analysis}

The FTIR technique was used to keep a tag on the modifications in the intensity of the characteristic bands of functional groups present before and after methylation reaction of the delignified mango seed.

The samples of delignified mango seeds (DSE) and methylcelluloses (MCD and MCI) were analyzed by FTIR, and the spectra were obtained in an IR Prestige-21 FTIR Spectrophotometer (Shimadzu). The samples were prepared using a mixture of the material with $\mathrm{KBr}$ at a proportion of 1:100 (w/w). For all spectra, 28 scans were used with a resolution of $4 \mathrm{~cm}^{-1}$.

\section{$X$ ray diffraction $(X R D)$ analysis}

The samples of delignified mango seeds (DSE) and methylcelluloses (MCD and MCI) were analyzed by using XRD analysis. The experiments were performed with a Shimadzu Diffractometer XRD 6000 using $\mathrm{K} \alpha \mathrm{Cu}$ radiation of $5^{\circ}$ to $80^{\circ}$ and $\mathrm{Ni}$ filter. The diffractograms obtained were deconvoluted in peaks and halos referring to the contributions of the crystalline and amorphous regions, respectively. The crystallinity of the samples was quantified using the following Equation 1:

$$
C(\%)=\frac{A_{c}}{A_{c}+A_{a}} \times 100
$$

where $A_{c}$ and $A_{a}$ are the areas under the crystalline peaks and amorphous halos, respectively. 


\section{Thermogravimetric analysis (TGA)}

Delignified mango seed (DSE) and methylcellulose (MCD and $\mathrm{MCI}$ ) samples were analyzed by TGA. The TGA curves were obtained in a Shimadzu DTG-60 using aluminum and alumina pans as reference. A $10 \mathrm{mg}$ sample was heated from room

Table 1. Compositions of the mortar samples.

\begin{tabular}{lccc}
\hline \multirow{2}{*}{ Components } & \multicolumn{3}{c}{ Mortar samples } \\
\cline { 2 - 4 } & CPV & CPV-MCD & CPV-MCI \\
\hline Portland cement (CPV-ARI) & $1,000 \mathrm{~g}$ & $1,000 \mathrm{~g}$ & $1,000 \mathrm{~g}$ \\
Medium sand & $3,930 \mathrm{~g}$ & $3,930 \mathrm{~g}$ & $3,930 \mathrm{~g}$ \\
Water & $700 \mathrm{~g}$ & $620 \mathrm{~g}$ & $620 \mathrm{~g}$ \\
MCD suspension & - & $200 \mathrm{~g}^{*}$ & - \\
MCI solution & - & - & $200 \mathrm{~g}^{*}$ \\
\hline
\end{tabular}

*The quantities of previously prepared aqueous suspension and solution of methylcellulose were added in such a way that the resulting polymer/cement ratio was $0.6 \%(\mathrm{w} / \mathrm{w})$.

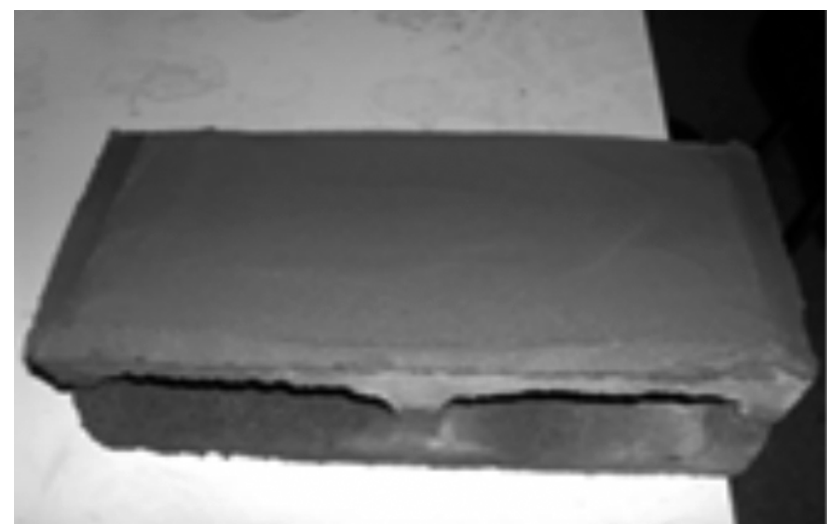

(a)

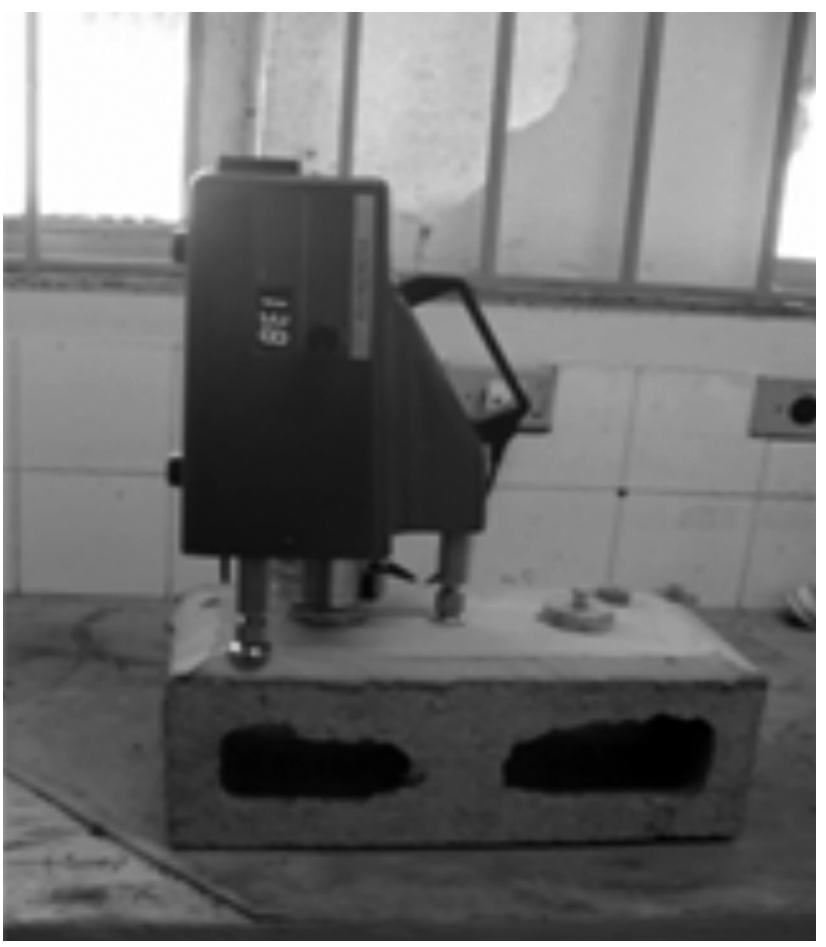

(c)

Figure 1. Pictures showing the bond tensile strength test. temperature to $600{ }^{\circ} \mathrm{C}$ at a heating rate of $10{ }^{\circ} \mathrm{C} / \mathrm{min}$, in a nitrogen atmosphere.

\section{Differential scanning calorimetry (DSC)}

The methylcellulose (MCD and MCI) samples were analyzed by DSC. The DSC analyses were performed with a TA Instruments Q-20, using $5 \mathrm{mg}$ of sample sealed in aluminum pans and a heating ramp of 25 to $300{ }^{\circ} \mathrm{C}$, under a nitrogen flux of $50 \mathrm{~cm}^{3} / \mathrm{min}$, with a heating rate of $10^{\circ} \mathrm{C} / \mathrm{min}$.

\section{Viscosity measurements}

Delignified mango seed (DSE) and methylcellulose (MCD and MCI) samples were submitted to viscosity analysis in cupriethylenediamine (CUEN) solution, according to the procedure described in the ABTCP (IPT) standard C26-1996. This procedure consists in the dissolution of material in CUEN and measures of flow time of this solution using a capillary viscometer of Ostwald, immersed in a water bath at $25^{\circ} \mathrm{C}^{[26]}$.

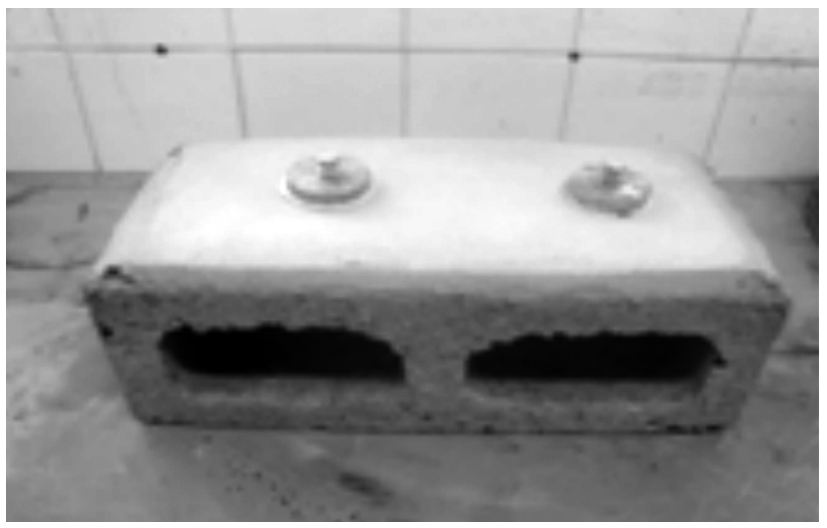

(b)

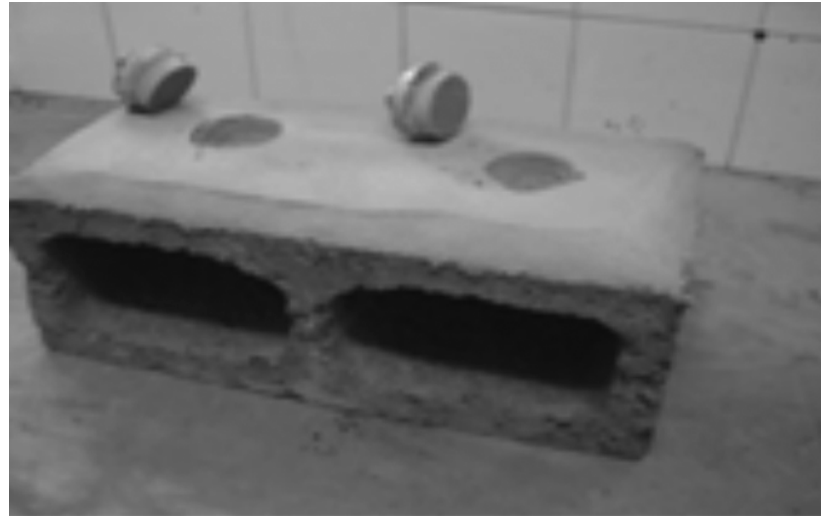

(d) 


\section{Use of methylcellulose as a mortar additive}

\section{Preparation of the methylcellulose (MCD) suspension}

Due to the unusual behavior of the aqueous solutions of MC, the suspension used to prepare the mortar was produced in two stages: i) mixing the MCD in water at $80{ }^{\circ} \mathrm{C}$ to speed up the process of water accessibility to the polymer and ii) cooling the solution temperature to $4{ }^{\circ} \mathrm{C}$, in order to increase polymer solubility, since at this temperature, the water molecules are organized in enclosed structures that surround the hydrophobic groups in the polymeric chains, weakening the association between them ${ }^{[20]}$. The procedure is summarized below:

- A mixture of MCD (6.00 g) with $200.0 \mathrm{~mL}$ of distilled water was shaken at $80{ }^{\circ} \mathrm{C}$ for 1 hour ${ }^{[20]}$. Then the suspension was cooled to ambient temperature and stored in a refrigerator at $4{ }^{\circ} \mathrm{C}$ for 24 hours. This quantity of polymer was used to maintain a polymer/cement ratio of $0.6 \%(\mathrm{w} / \mathrm{w})$.

\section{Preparation of the methylcellulose (MCl) solution}

Six $\mathrm{g}$ of MCI were weighed and $200 \mathrm{~mL}$ of distilled water added. The mixture was shaken at $25^{\circ} \mathrm{C}$, until all the solid material was completely solubilized.

\section{Mortar mixtures preparation}

The mortar mixtures were prepared using Initial High Strength Portland cement (CPV-ARI) according to Brazilian standard NBR 5733. The mortar components are described in Table 1.

In order to control granulometry of the medium grain sand, a 4 mesh sieve was used with a $4.76 \mathrm{~mm}$ opening.

\section{Consistency index $(\mathrm{Cl})$ measurement}

The consistencies of the different samples of fresh mortars (CPV, CPV-MCD and CPV-MCI) were evaluated using a slump table according to Brazilian standard NBR 7215. The fresh mortar is placed on a slump table, which is spun thirty times, then two orthogonal diameters are collected using a caliper rule and the consistency index value is given by the arithmetic average.

The trials for consistency index (CI) were carried out three times on the same day in the same conditions of temperature and relative humidity.

\section{Bond tensile strength (TS) test}

The tests to determine the bond tensile strength were performed according to standard NBR 15258/2005, for the different mortar samples (CPV, CPV-MCD and CPV-MCI).

This test was carried out after 28 curing days. The curing process is the time interval that corresponds to the initial reactions of the cement hydration and hardening of the mortar. The time, the humidity conditions and the temperature have a significant influence in all the properties of the material, therefore special care must be taken to allow, physically and chemically, for the constitution of the cement matrix. The curing process was carried out during the period of 28 days at $24{ }^{\circ} \mathrm{C}( \pm 4)$ and relative humidity around $50 \%$.

In order to perform the bonding tests, concrete structural blocks measuring $39 \mathrm{~cm}$ in length, $19 \mathrm{~cm}$ in width and $19 \mathrm{~cm}$ in height were used. The pastilles used had a round shape, measuring $5 \mathrm{~cm}$ in diameter and were put in the mortar using an epoxy resin of high adherence. After curing for 28 days, the pastilles were removed using a digital Pavitest ${ }^{\circledR}$ Adhesiometer to pull out and measure adhesion in mortars. Figure 1 shows the bond tensile strength test.

The maximum tension recorded by the equipment when the pastilles are pulled out, represents the bond tensile strength of the aforementioned mortar. The trials for bond tensile strength (TS) were carried out three times on the same day in the same conditions of temperature and relative humidity.

\section{Results and Discussion}

\section{Characterization of crude mango seed (CS) and delignified mango seed (DSE)}

Crude mango seed (CS) and delignified seed (DSE) fibers were characterized for cellulose and Klason lignin contents. The cellulose contents obtained were 55.0 and $86.1 \%$ and Klason lignin contents obtained were 23.8 and $0.1 \%$, for crude seed (CS) and for delignified seed (DSE), respectively.

The lignin content of the crude Ubá mango seed is equivalent to the other sources of cellulose, such as sugar cane bagasse $(24 \%)^{[1]}$. However, the cellulose content of crude seed is greater than that of sugarcane bagasse which is approximately $45 \%^{[1]}$. These results show the potential for investment in this source to produce cellulosebased products.

After the delignification process, the Klason lignin content, measured for the delignified mango seed (DSE) was $0.1 \%$, indicating the effectiveness of the delignification process used in this study. With this low lignin content, the material can be used for methylation reactions, since the presence of high lignin content, above 5\% limits the methylation reaction. There are lignin groups that can interact with the methylating agent during the etherification process, thus leading to a mistaken estimate of the degree of methylcellulose substitution ${ }^{[27]}$.

\section{Cellulose (DSE) and methylcellulose (MCD and MCI) sample characterization by FTIR, DS and viscosity}

The efficiency of the methylation processes using DMS and iodomethane can be found comparing the infrared spectra of the delignified seed (DSE) and methylcellulose (MCD and MCI) samples (Figure 2).

Comparing the spectrum of purified cellulose (DSE) with the spectra of the methylcellulose samples (MCD and MCI), the main changes observed were band intensity reduction around $3500 \mathrm{~cm}^{-1}$ attributed to stretching the $\mathrm{O}-\mathrm{H}$ bond (hydroxyl groups) of cellulose, which was partially substituted by methyl groups during the methylation reaction, and the increased intensity of the bands between $2750-2900 \mathrm{~cm}^{-1}$ which are attributed to the stretching of C-H aliphatics ${ }^{[1,16,20]}$.

However, comparing delignified mango seed (DSE) spectra to spectra of the two methylcellulose (MCD and MCI) samples, a closer relationship is found between the $\mathrm{C}-\mathrm{H}$ and $\mathrm{O}-\mathrm{H}$ bands for DSE and MCD samples. This evidence can be confirmed quantitatively determining the ratio between bands $\mathrm{C}-\mathrm{H}\left(2920 \mathrm{~cm}^{-1}\right)$

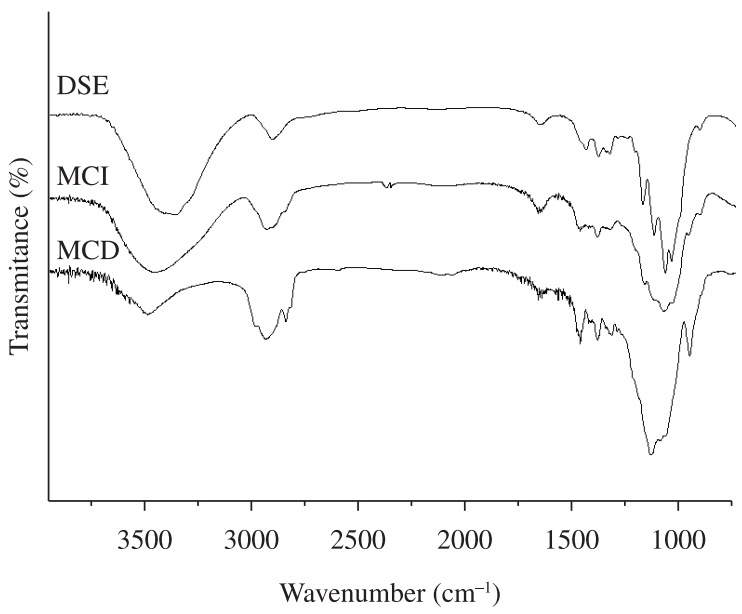

Figure 2. FTIR spectra for DSE, MCD and MCI samples. 
and $\mathrm{O}-\mathrm{H}\left(3500 \mathrm{~cm}^{-1}\right)$. For this purpose the spectra were normalized in relation to the band at $1110 \mathrm{~cm}^{-1}$ which is attributed to stretching the $\mathrm{C}-\mathrm{O}-\mathrm{C}$ bond of an anhydroglycoside ring. For the delignified mango seed (DSE) cellulose, the $(\mathrm{C}-\mathrm{H}) /(\mathrm{O}-\mathrm{H})$ ratio was 0.26 while for the methylcellulose MCD and MCI samples, it was 1.50 and 0.55 , respectively, showing that the degree of substitution of methyl groups in the MCD sample was greater than in the MCI sample. This evidence was confirmed by chemically obtained DS values, which were 1.30 and 0.47 for the MCD and MCI samples, respectively.

The viscosimetric molecular mass for the DSE fibers was $69,000 \mathrm{~g} \cdot \mathrm{mol}^{-1}$, and the relative viscosity of the solution was 3.57. The relative viscosities of the solutions prepared under the same conditions as the DSE for MCI and MCD were 2.63 and 1.42, respectively. All indications are that the synthesis pathway using iodomethane preserves the size of the polymer chains.

According to the literature ${ }^{[19]}$, in the methylation processes using iodomethane there is competition between methanol formation, and dimethylic ether may also be formed together with methylcellulose. The chemical Equation 2 below shows the formation of these byproducts.

$$
\begin{aligned}
& \mathrm{CH}_{3} \mathrm{I}+\mathrm{NaOH} \rightarrow \mathrm{CH}_{3} \mathrm{OH}+\mathrm{NaI} \\
& \mathrm{CH}_{3} \mathrm{OH}+\mathrm{CH}_{3} \mathrm{I}+\mathrm{NaOH} \rightarrow \mathrm{CH}_{3} \mathrm{OCH}_{3}+\mathrm{NaI}+\mathrm{H}_{2} \mathrm{O}
\end{aligned}
$$

Therefore, although synthesis with iodomethane takes longer, methylation is more effective with DMS. This was previously proved by the FTIR spectra and by the values of DS, which were higher for MCD (1.30) than for MCI (0.47).

\section{$X R D$ characterizations}

Figure 3 shows the diffractograms of delignified mango seed (DSE), methylcellulose (MCD and MCI) samples.

When comparing the XRD patterns of MC samples with the diffractogram of cellulose, we can highlight the maximum at $8^{\circ}$ for $\mathrm{MCD}$, that is not present in the diffractogram of cellulose, which according to the literature ${ }^{[17]}$ is attributed to cellulose modification. The latter's position indicates an increase in the interplanar distance compared to the original cellulose diffractogram, due to the generation of disorder when the cellulose is modified. The projection of the substituting groups along the axis (methyl groups) is associated with an increase in the interfibrillar distance. This maximum is not very visible in $\mathrm{MCI}$, showing a small modification of the cellulose structure due to the low degree of substitution presented ${ }^{[17,28]}$.

The maximum around $20^{\circ}$, present in all samples is called the van der Waals halo. This maximum appears in all polymers and corresponds to the polymeric chain packing due to the van der Waals forces ${ }^{[28]}$. We can also highlight the maximum around $10^{\circ}$ that is known as halo of low van der Walls. It occurs for some amorphous polymers due to the existence of regions with aggregates of segments of parallel chains ${ }^{[28]}$. The two samples of methylcellulose present this maximum at $10^{\circ}$, indicating substitution, although intensity is low for MCI. In the case of MCD, this maximum is much more clearly defined in its half height width, which gives to this sample a more semicrystalline character. This is corroborated by crystallinity index values $(\mathrm{C} \%)$ obtained which were $52.6 \%$ for $\mathrm{MCD}, 30.4 \%$ for MCI and $61.2 \%$ for cellulose. The MCD sample presents a more crystalline pattern than MCI, which agrees with the degree of substitution obtained for it (1.30). In the synthesis process with iodomethane the fibers undergo two mercerization processes during the 44 hours of reaction. Mercerization promotes an expansion of the cellulose chains, increasing the portion of less ordered material and reducing the crystalline portion. The second mercerization stage allows methylation to occur both in the crystalline and the amorphous regions.
Methylation using DMS, on the contrary, occurs preferentially in the amorphous regions, preserving the crystalline regions, consequently there is less solubility. It is also likely that polymer chain packing is better in material with a higher DS value due to more interaction between the hydrophobic blocks, improving the organization of the system.

Moreover, these crystallinity patterns influence the solubility properties of the materials produced. Since MCD presents a higher crystallinity index, it is not water-soluble at room temperature, and must undergo a heating and cooling cycle to form a suspension. On the other hand, the MCI sample is more amorphous, more accessible to solvents, and therefore it dissolves in water at room temperature.

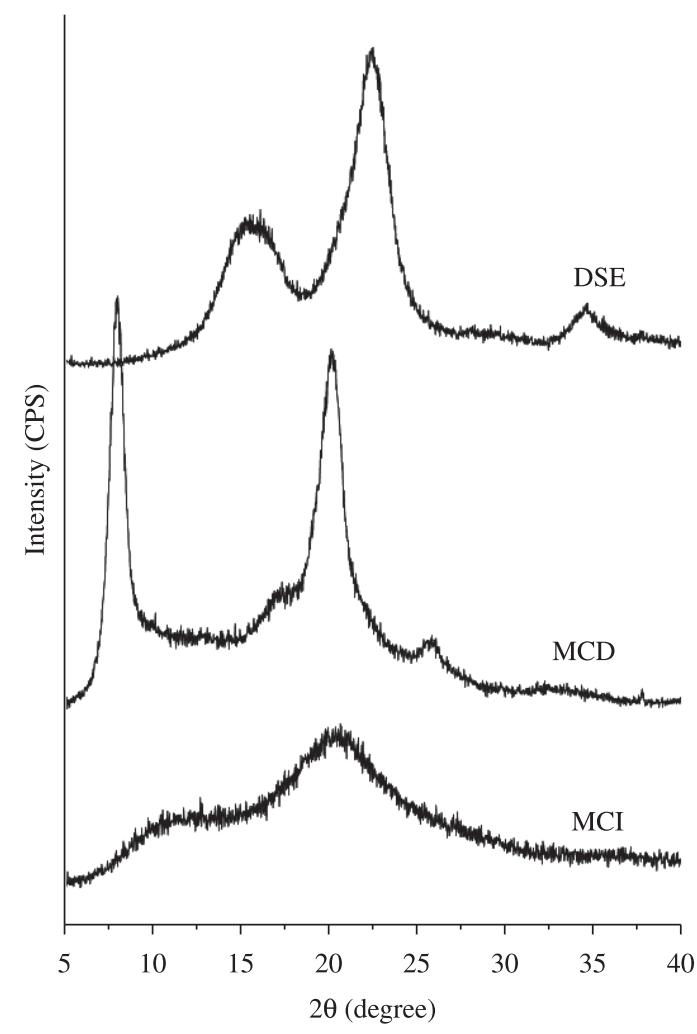

Figure 3. Diffractograms of DSE, MCD and MCI samples.

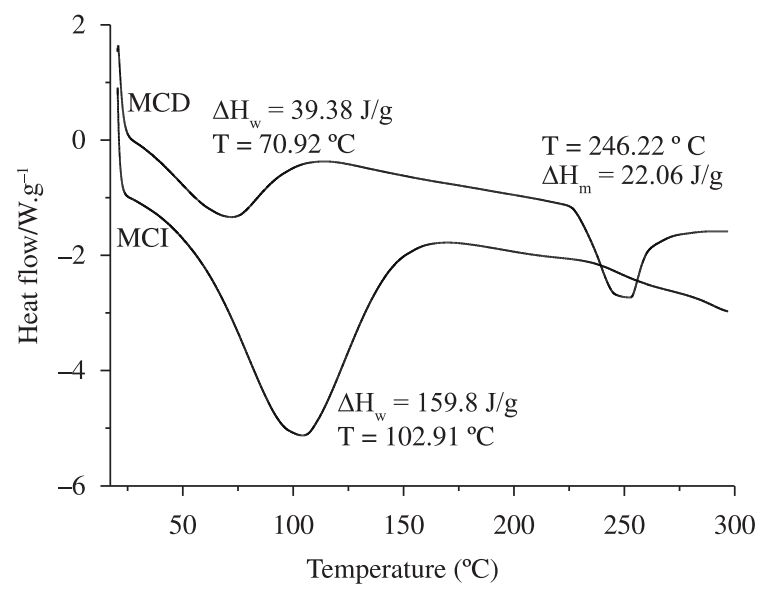

Figure 4. DSC curves for MCD and MCI samples. 


\section{Characterizations by DSC and TGA}

Figure 4 presents the DSC thermograms for MCD (a) and MCI (b) samples.

From the DSC thermograms for samples MCD and MCI, it can be seen that the water flow endotherm occurs at different temperatures for the two samples. For MCD the water loss temperature is $70.92{ }^{\circ} \mathrm{C}$ and the enthalpy is $39.38 \mathrm{J.g}^{-1}$, indicating that interaction between the water molecules and this polymer is less intense compared to MCI, whose water outflow temperature

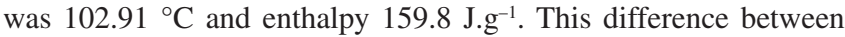
enthalpy and water outflow temperature corroborates the DS values presented previously, and also the crystallinity indexes, because the crystalline regions are less accessible to solvents than the amorphous regions and water is probably more weakly linked to the hydroxyls in these regions.

From the thermograms we can find an endotherm at $246.22{ }^{\circ} \mathrm{C}$ for the MCD sample that can be attributed to the fusion of crystalline regions of methylcellulose ${ }^{[16,17]}$. On the other hand, the thermogram for the MCI sample does not present a fusion endotherm.

Figure 5 shows the TGA thermograms of the DSE, MCD and MCI samples. The thermograms present an initial mass loss stage corresponding to loss of water that is connected to the "bonding sites' of the polymers molecules (hydroxyl groups). The loss of mass at this stage was $8 \%$ for DSE, $6 \%$ for MCD and $15 \%$ for MCI, indicating a smaller amount of water absorbed for the sample MCD. This difference can be explained as a function of the substitution of $\mathrm{OH}$ groups by $\mathrm{OCH}_{3}$ groups, during the methylation reaction, reducing the number of hydroxyls available to interact with the water molecules.

According to the literature, methylcellulose has a single decomposition stage and the temperature range at which this phenomenon occurs is from $324.7{ }^{\circ} \mathrm{C}$ to $415.0{ }^{\circ} \mathrm{C}^{[29]}$. The presence of the endotherm around $250{ }^{\circ} \mathrm{C}$ in the DSC thermogram of MCD and the fact that methylcellulose decomposition occurs between 324.7 and $415.0^{\circ} \mathrm{C}$ confirm that the endotherm in DSC is attributed mainly to the fusion. However, this phenomenon is accompanied by degradation, as shown by the results in Figure 4. On the other hand, the MCI sample does not present a fusion endotherm in DSC and its degradation begins around $300{ }^{\circ} \mathrm{C}$, confirming the more amorphous pattern for this sample, as previously demonstrated by the $\mathrm{X}$ ray diffractograms. Therefore, MCD is thermally more stable than MCI and less stable than original cellulose, as seen in the TGA curves.

\section{Results of methylcellulose as a mortar additive}

The basic and essential property of a tile-laying and mortar coating system is adhesion. In this paper, mortars were produced with adhesive properties for tile-laying and their workability properties and adhesion were investigated. The workability of mortar was evaluated using the consistency index (CI) shown in Table 2.

Both samples containing methylcellulose (CPV-MCD and CPV$\mathrm{MCI}$ ) were effective to increase the consistency index (CI) compared to the reference mortar (CPV). Sample CPV-MCD promoted a $27.75 \%$ increase and the CPV-MCI sample led to a $71.54 \%$ increase in CI. An important aspect to explain the increased CI is the improved mixture of the mortar components, due to better system lubrication. According to Khayat ${ }^{[13]}$, the cellulose ethers (water retainers), and also methylcellulose in cement-based materials act mainly to modify the viscosity of the aqueous phase of the mixture, since, due to their hydrophilic nature (presence of hydroxyl groups, $\mathrm{OH})$, the water molecules bind to the additive molecules. Thus, there is more water retention and increased viscosity ${ }^{[13]}$.

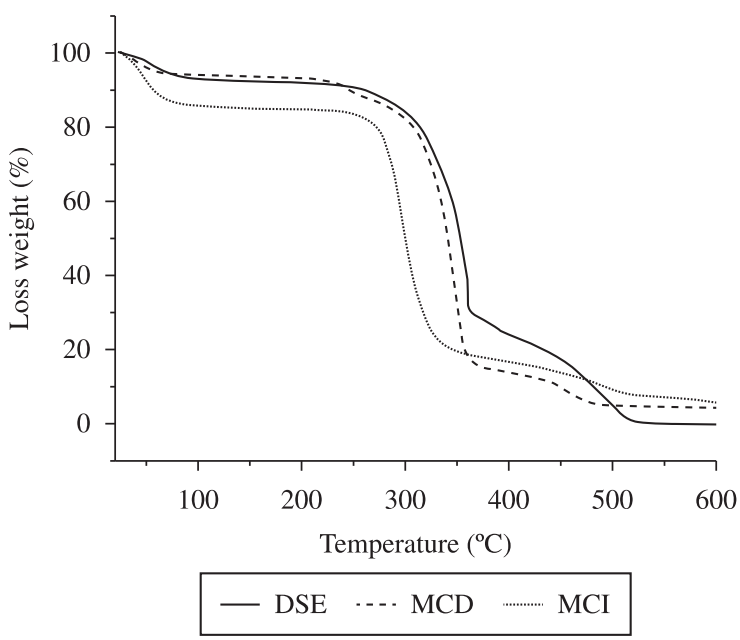

Figure 5. TGA thermograms for DSE, MCD and MCI samples.

Table 2. Results of the Consistency Index (CI) and Bond Tensile Strength (TS) tests of the mortars.

\begin{tabular}{ccc}
\hline Samples & $\begin{array}{c}\text { Consistency index } \\
(\mathbf{m m})\end{array}$ & $\begin{array}{c}\text { Bond tensile strength } \\
(\text { TS })(\mathbf{M P a})\end{array}$ \\
\hline CPV & $168.04 \pm 1.70$ & $0.30 \pm 0.01$ \\
CPV-MCD & $214.68 \pm 0.04$ & $0.37 \pm 0.02$ \\
CPV-MCI & $288.25 \pm 1.91$ & $0.38 \pm 0.02$ \\
\hline
\end{tabular}

Figure 6 shows the difference in CI when the reference mortar (CPV) is compared to mortars CPV-MCD and CPV-MCI with methylcellulose as an additive.

The mortars are clearly more homogenous and cohesive with the polymers ${ }^{[30]}$. Adding water to the mortar without adding polymers diminishes viscosity but, on the other hand, causes segregation the mixture components. Therefore, using the polymer creates greater cohesion among the mortar components, allowing greater fluidity ${ }^{[30]}$.

The adhesive properties of the different mortars were evaluated through a test of bond tensile strength (TS). The results obtained after 28 days of normal curing are shown in Table 2.

Both samples containing methylcellulose (CPV-MCD and CPV$\mathrm{MCI}$ ) improved mortar adhesion to the substrate compared to reference mortar (CPV). Sample CPV-MCD showed a $23.33 \%$ increase in adhesion and sample CPV-MCI showed an increase of $29.78 \%$.

The Bond Tensile Strength (TS) values are standardized by ABNT NBR 15258/2005 that establishes minimum TS values for mortars with different applications. Comparing the values of TS obtained for mortars with additives to the different samples of methylcellulose with standardized values, it is possible to verify that the latter TS values are above the range established for high performance mortars found in classifications for laying tiles and coating walls and ceilings, where high performance mortar presents a potential resistance value of adhesion to traction greater than or equal to $0.30 \mathrm{MPa}$.

Since methylcellulose is a polymer that presents non-substituted hydroxyl groups, it retains water in the mortar structure, preventing losses to the substrate and to the atmosphere by evaporation ${ }^{[21,30]}$. The greater water retention by mortar improves the occurrence of cement hydration reactions, allowing greater adhesion between the mortar structure and the substrate.

The difference in TS observed between the mortars containing the different samples of methylcellulose $(0.37 \mathrm{MPa}$ for CPV-MCD and $0.38 \mathrm{MPa}$ for CPV-MCI) is minimal, but it is to be expected that mortar to which a polymer with greater water retention capacity is added will be more adhesive. 


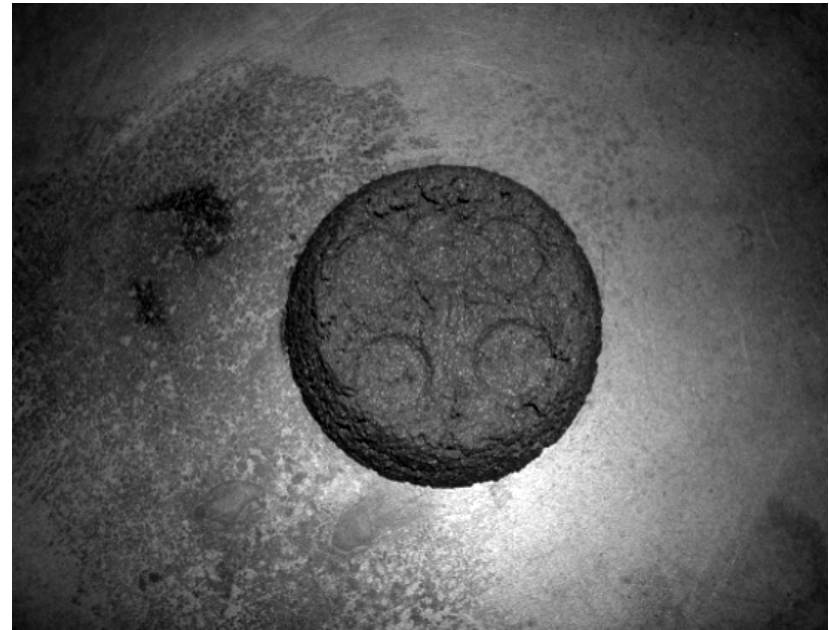

(a)

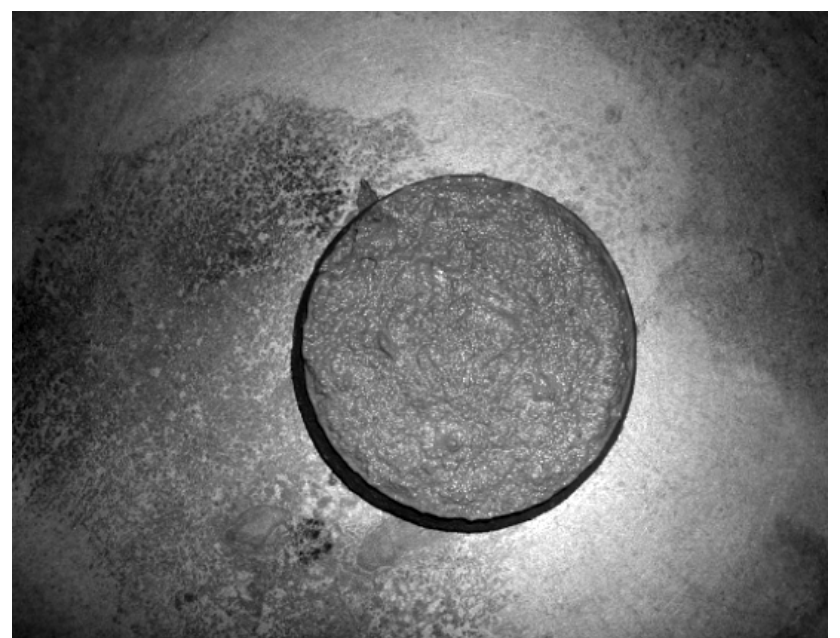

(c)

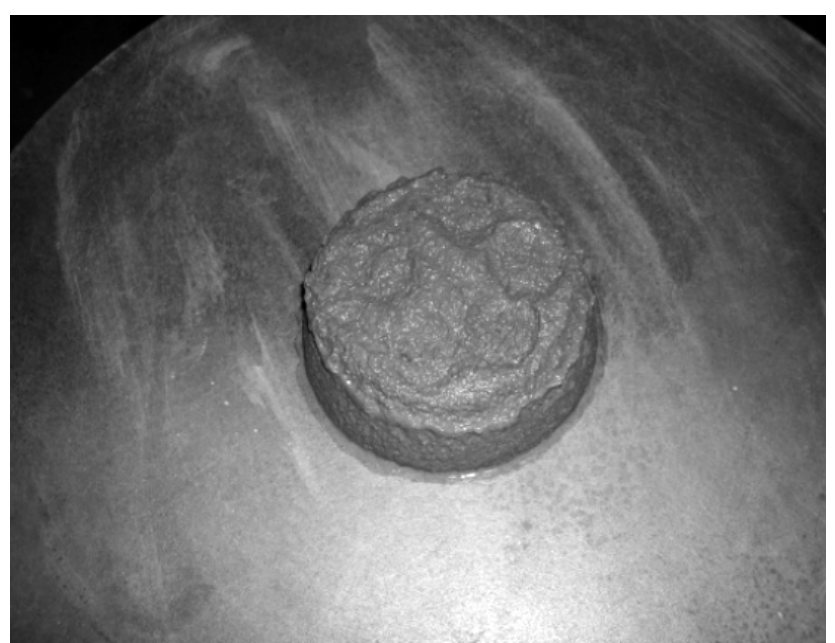

(e)

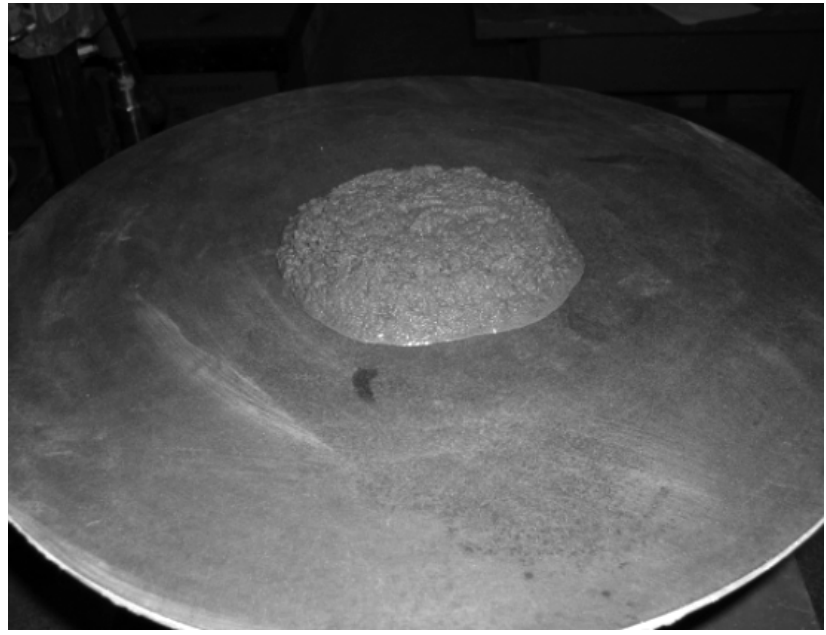

(b)

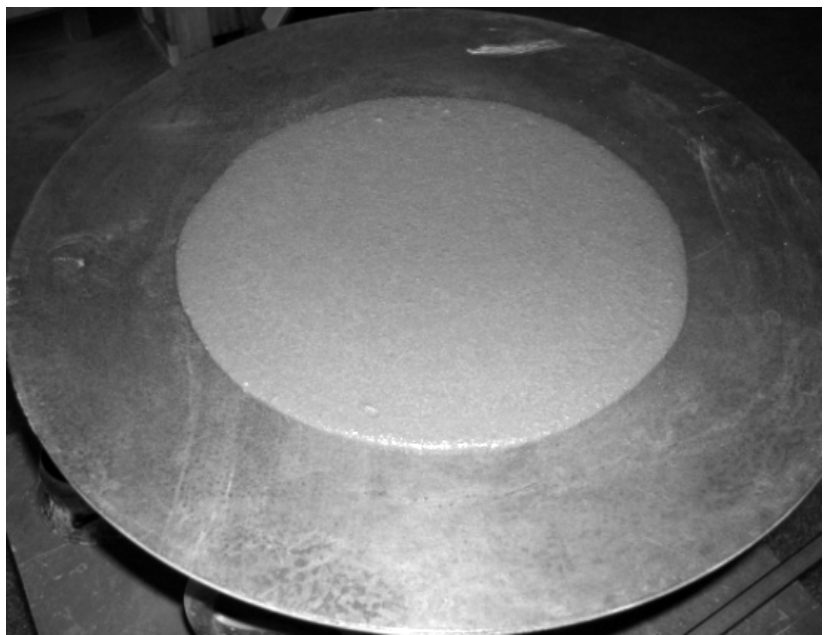

(d)

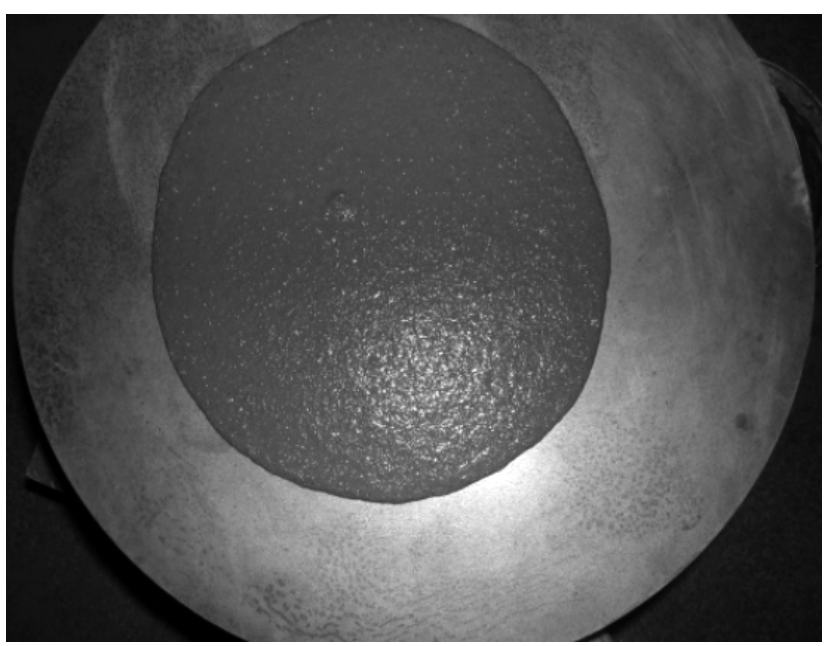

(f)

Figure 6. Physical aspect of mortar during the test to determine the consistency index: a) CPV; c) CPV-MCI; and e) CPV-MCD before the test; b) CPV; d) CPV-MCI; and f) CPV-MCD after the test. 


\section{Conclusions}

The results showed that mango seeds are a source of cellulose that can be used to produce methylcellulose, thus reducing the impact caused when this residue is discarded. The different methylation processes led to the production of methylcellulose with different degrees of crystallinity and molecular structure modification. The methylcellulose samples produced have presented good characteristics when applied as mortar additive, both in the fresh state, increasing the consistency index (CI) and, after curing, improving the results of bond tensile strength (TS). The CI values were 214.68 and $288.25 \mathrm{~mm}$, while those of TS were 0.37 and $0.38 \mathrm{MPa}$ for the mortars containing MCD and MCI, respectively. The results obtained are higher than the minimum values required for mortar coatings in different applications, justifying the applicability of the polymers produced from this biomass.

\section{Acknowledgements}

The authors thank CAPES for financial support and for providing the periodicals portal (www.periodicos.capes.gov.br), $\mathrm{CNPq}$ for financial support through project "Projeto Casadinho", Agreement UFU/UFG/UFMS (620181/2006-0), and FAPEMIG for project EDT-88/07. Vieira thanks FAPEMIG and Meireles thanks CAPES, for their PhD scholarships.

\section{References}

1. Vieira, R. G. P.; Rodrigues Filho, G.; Assunção, R. M. N.; Meireles, C. S.; Vieira, J. G. \& Oliveira, G. S. - Carbohydr. Polym.,67, p.182 (2007).

2. Sun, J.X.; Sun, X.F.; Zhao, H. \& Sun, R.C. - Polym. Degrad. Stab.,84, p.331 (2004).http://dx.doi.org/10.1016/S0141-3910(04)00045-X

3. Packaging Greener. - "Making packaging greener-Biodegradable Plastics". Disponívelem: http://www.science.org.au/ nova/061/061 print.htm. Acessoem: 23jan. 2006.

4. Pandey, A.; Soccol, C. R; Nigam, P. \&Soccol, V.T. - Bioresour. Technol. 74, p.69 (2000). http://dx.doi.org/10.1016/S0960-8524(99)00142-X

5. Favero, L. A. - "A cultura da manga no São Francisco: posicionamento, limites, oportunidades e ações estratégicas", Banco do Nordeste do Brasil, Fortaleza (2008).

6. Damiani, C.; Vilas Boas, E. V. B.;Soares Junior, M. S.; Caliari, M., Livramento de Paula, M., Pereira, D. E. P. \& Silva, A. G. M. Ciência Rural, 38, p.1418 (2008).http://dx.doi.org/10.1590/S010384782008000500035

7. Meireles, C. S.; Mundim, E. A.; Silva, J. V. V.; Bragança, M. H.; Alves, A. C.; Cerqueira, D. A.; Assunção, R.M.N. \& Rodrigues Filho, G.

- "Estudo da incorporação de paracetamol em matrizes de acetato de celulose produzidos a partir da celulose do caroço de manga purificado", in:Anais do $10^{\circ}$ Congresso Brasileiro de Polímeros - Foz do Iguaçu - PR, outubro (2009).

8. Meireles, C. S.; Rodrigues Filho, G.; Ferreira Junior, M. F.; Cerqueira, D. A.; Assunção, R. M. N.; Ribeiro, E. A.; Poletto, P. \& Zeni, M. Carbohydr. Polym.,80, p.954 (2010).http://dx.doi.org/10.1016/j. carbpol.2010.01.012

9. Cruz, S. F.; Rodrigues Filho, G.; Vieira, J. G.; Assunção, R. M.N. \&Pasquini, D. - "Síntese e caracterização de metilcelulose a partir da celulose extraída do caroço de manga", in: Anais do $10^{\circ}$ Congresso Brasileiro de Polímeros, Foz do Iguaçu - PR, outubro (2009).
10. Fu, X. \& Chung, D.D.L. - Cem. Concr. Res., 26, p.189 (1996a). http:// dx.doi.org/10.1016/0008-8846(95)00201-4

11. Xue, J. \&Ngadi, M. - FoodHydrocoll.,23, p.286 (2009).http://dx.doi. org/10.1016/j.foodhyd.2008.01.002

12. Ye, D.Y. \&Farriol, X. - Ind. Crops Prod., 26, p.54 (2007).http://dx.doi. org/10.1016/j.indcrop.2007.01.004

13. Khayat, K. H. - Cem. Concr. Compos.,20, p.171 (1998).http://dx.doi. org/10.1016/S0958-9465(98)80006-1

14. Pourchez, J.; Grosseau, P.; Guyonnet, R. \&Ruot, B. - Cem. Concr. Res.,36, p.1777 (2006).http://dx.doi.org/10.1016/j. cemconres.2006.06.002

15. Silva, D. A. \& Monteiro, P. J. M. - Cem. Concr. Res., 36, p.1501 (2006). http://dx.doi.org/10.1016/j.cemconres.2006.05.010

16. Oliveira, G. C.; Rodrigues Filho, G.; Vieira, J. G.; Assunção, R. M. N.; Meireles, C. S.; Cerqueira, D. A.; Oliveira, R. J.; Silva, W. G. \& Motta, L. A. C. - J. Appl. Polym. Sci., 118, p.1380 (2010)

17. Rodrigues Filho, G.; Assunção, R. M. N.; Vieira, J. G.; Meireles, C. S.; Cerqueira, D. A.; Barud, H. S.; Ribeiro, S. J. L. \&Messadeq, Y. Polym. Degrad. Stab. 92, p.205 (2007).

18. Ke, H.; Zhou, J. \& Zhang, L. - Polym. Bull., 56, p.349 (2006).http:// dx.doi.org/10.1007/s00289-006-0507-5

19. Majewicz, T. G.; Erazo-Majewicz, P. E. \&Podlas Thomas J. - “Cellulose ethers", in: Encyclopedia of Polymer Science and Technology Mark", Herman F., Wiley-Interscience, New York, p. 507 (2004).

20. Vieira, J. G.; Oliveira, G. C.; Rodrigues Filho, G.; Assunção, R. M. N.; Meireles, C. S.; Cerqueira, D. A.; Silva, W. G. \& Motta, L. A. C. - Carbohydr. Polym.,78, p.779 (2009).http://dx.doi.org/10.1016/j. carbpol.2009.06.016

21. Knapen, E. \&Gemert, D. V. - Cem. Concr. Res., 39, p.6 (2009).http:// dx.doi.org/10.1016/j.cemconres.2008.10.003

22. Fu, X. \& Chung, D.D.L. - Cem. Concr. Res., 26, p.535 (1996b).

23. Hou, J. \&Chung, D.D.L. - Corros. Sci.,42, p.1489 (2000).http:// dx.doi.org/10.1016/S0010-938X(99)00134-1

24. Technical Association of the Pulp and Paper Industry - TAPPI. "Standard TAPPI T222 om-02. Acid-insoluble lignin in wood and pulp", TAPPI (2002)

25. Technical Association of the Pulp and Paper Industry - TAPPI. "Standard TAPPI T235 cm-00. Alkali solubility of pulp at $25^{\circ} \mathrm{C}$ ", TAPPI (2000)

26. Associação Brasileira Técnica de Celulose e Papel - ABTCP. "Standard C26-1996:Pasta celulósica - Determinação de viscosidade intrínseca em solução de cuproetilenodiamina (CUEN) com viscosímetro tipo capilar", ABTCP (1996).

27. Vieira, R. G. P. “"Síntese e caracterização da metilcelulose a partir da metilação heterogênea do bagaço de cana-de-açúcar", ,issetaçăo de Mestrado, Federal University of Uberlândia, Brazil (2004).

28. Rodrigues Filho, G.; da Cruz, S. F.; Pasquini, D.; Cerqueira, D. A.; Prado, V. S. \& Assunção, R. M. N. - J. Membr. Sci.,177, p.225 (2000).

29. Zohuriaan, M.J. \&Shokrolahi, F. - Polym. Test,23, p.575 (2004).http:// dx.doi.org/10.1016/j.polymertesting.2003.11.001

30. Paiva, H.; Silva, L.M.; Labrincha, J.A. \& Ferreira, V.M. - Cem. Concr. Res., 36, p.1257 (2006).http://dx.doi.org/10.1016/j. cemconres.2006.02.018

Enviado: $13 / 12 / 10$ Reenviado: 14/04/11 Aceito: 28/05/11 